\begin{tabular}{lc}
\hline SCIENCE \& TECHNOLOGY \\
Journal homepage: http://www.pertanika.upm.edu.my/ \\
\hline PERTANIKA
\end{tabular}

\title{
Artificial Neural Network Intelligent System on the Early Warning System of Landslide
}

\author{
Aghus Sofwan ${ }^{1 *}$, Sumardi ${ }^{1}$, Najib ${ }^{2}$ and Indrah Wendah Atma Bhirawa ${ }^{1}$ \\ ${ }^{1}$ Department of Electrical Engineering, Diponegoro University, Jalan Prof. Soedarto SH, Semarang, Indonesia \\ ${ }^{2}$ Department of Geological Engineering, Diponegoro University, Jalan Prof. Soedarto SH, Semarang, Indonesia
}

\begin{abstract}
Landslide is a natural sloping ground movement disaster that can occur due to several factors such as high rainfall, soil moisture in the depth of the soil of an area, vibrations experienced in the region, and the slope of the ground structure. A system that can deliver these factor values into the levels of vulnerability of landslide disasters is needed. The system uses Arduino Mega 2560 to process the level of vulnerability. It can predict the moment and the probability of the disaster occurring as an early warning system. The artificial neural network (ANN) intelligent system can expect an event of a disaster. The designed ANN used five parameters causing landslide as input data: rainfall, slope, soil moisture on the surface, soil moisture in the ground's depth, and soil vibration. The ANN system output delivered three-level conditions: the safe, the standby, and the hazardous. The feed-forward backpropagation (FFBP) and the cascade forward backpropagation (CFBP) methods were analyzed. The performance of both methods was compared in terms of minimum square error (MSE). The MSE results of FFBP and CFBP in the safe, the standby, and the hazardous conditions were 0.017076 and 0.034952 ; 0.049597 and $0.046764 ; 0.062105$ and 0.060355 ; respectively. The results point to the supremacy of CFBP to FFBP in standby

ARTICLE INFO

Article history:

Received: 13 November 2020

Accepted: 04 February 2021

Published: 30 April 2021

and hazardous conditions. Therefore, the CFBP is implemented into the hardware of the early warning system.
\end{abstract}

DOI: https://doi.org/10.47836/pjst.29.2.13

E-mail addresses:

asofwan@elektro.undip.ac.id (Aghus Sofwan)

sumardi@elektro.undip.ac.id (Sumardi)

najib@ft.undip.ac.id (Najib)

indrahwendah591996@gmail.com (Indrah Wendah Atma Bhirawa)

* Corresponding author
Keywords: Artificial neural network, cascade-forward backpropagation, feed-forward backpropagation, landslides 


\section{INTRODUCTION}

Landslides are natural disasters that occur as a result of sloping ground movements on a hillside or mountain. Indonesia also has a tropical monsoon marine climate with high rainfall. The tropical monsoon climate causes the reason for the landslides. The tropical monsoon climate has extreme changes in air pressure in almost resulting in high rainfall. Furthermore, it increases the soil water content, coupled with the soil vibration, which will trigger landslides (Huang \& Lin, 2002). According to released data from the National Disaster Management Agency Indonesia, the country has 274 cities with landslide potential (BNPB, 2019). The total number of natural disasters in this country from 2017 to 2019 is 1326 events, resulting in 642 fatalities and injuries (BNPB, 2019). Recognizing the changing pattern of each parameter will make it easier to predict when a landslide disaster occurs.

In the previous research, the utilization of artificial neural network (ANN) methods to recognize data patterns and forecasting have been carried out in many applications, such as biological (Gu et al., 2012), food (Stangierski et al., 2019), chemical (Radfard et al., 2018), environment (Li \& Jiang, 2010; Ul-Saufie et al., 2011), and disaster (Borujeni \& Nateghi, 2019; Elsafi, 2014; Pradhan \& Lee, 2010; Tsakiri et al., 2018). Notably, Pradhan and Lee (2010), used the backpropagation neural network to analyze landslide susceptibility. The result suggests the effect of the topographic slope. In Borujeni and Nateghi (2019), the ANN model was selected as a computational model for landslide forecasting, which only measured the soil layer displacement. Moreover, much practical research on the landslide warning system has been studied, such as in Chaturvedi et al. (2017), Chen et al. (2017), Hemalatha et al. (2019), and Sofwan et al. (2017). Sofwan et al. (2017) developed a wireless sensor network that applied Internet of Things architecture for landslide warnings. Chen et al. (2017) used a probability regression model to detect landslide and applied it in practical cases. Chaturvedi et al. (2017) used sensor data to develop a landslide early warning system (EWS). Hemalatha et al. (2019) applied machine learning algorithms, which supported vector regression for wireless sensor networks for real-time monitoring and early warning of a landslide. Nguyen et al. (2019) proposed the hybrid machine learning models, such as Particle Swarm Optimization for Adaptive Neuro Fuzzy Inference System and Particle Swarm Optimization for Artificial Neural Networks for landslide spatial prediction. The proposed models provide MSEs with value of 0.225 and 0.312 , respectively. Hereafter, in our research, we considered implementing the ANN model. The model used either the feed-forward backpropagation (FFBP) or cascade-forward backpropagation (CFBP) method. The chosen method would then be embedded into an early warning hardware system to identify a landslide disaster level. Our research contribution is more focused on developing the ANN model with FFBP and CFBP methods. Whereas, Sofwan et al. (2018a) 
published our hardware system development. The hardware is the node, which consists of sensors, microcontroller Arduino Mega 2560, communication module, and solar cell power supply. The sensors measure rainfall, soil moisture, temperature, and air humidity. The microcontroller processes the measurement sensor results with ANN. Furthermore, the processing result is submitted to the server as information for the stakeholder. The node is placed at remote area so that it is equipped with the solar cell power supply.

\section{METHODS}

An ANN is a system inspired by human neuron information processing to learn a particular procedure. The ANN construction is achieved by giving excitement into the neuronal fashion, computing the output, and adjusting the weights until the expected result is obtained. In this research, the ANN was used to identify conditions and assessed a landslide vulnerability. The main steps of the conducted research were as follows. Firstly, the 10,000 static training data was collected as the input of a model with computational programming. The data was referred to the parameters of landslide causes, based on the Ministry of Public Works Regulation of Indonesia (PMPU) No.22/PRT/M/2007 (Ministry of Public Work Regulation, 2007), obtained from sensor measurement except for vegetation. The regulation is used as a basis for regulating landslide-prone areas in Indonesia. Therefore, we use this regulation to apply the weight of landslide parameters. The weight values, i.e., 1 to 3 , and weighting percentage values, are applied to the parameters shown in Table 1. Percentage of weighting for rainfall, slope, soil moisture, vibration, and vegetation are $30 \%, 15 \%$, $22 \%, 23 \%$, and $10 \%$, respectively. The main factor of landslide cause is rainfall so that the regulation applies the weight value of $30 \%$. The total weighting percentage is 100 per cent, hereafter, and is utilized as the manual calculation for the landslide vulnerabilities resulting in some output levels. The output is classified into three ranges: 1.00-1.69, 1.702.39, and 2.40-3.00 refer to safe, standby, and hazard situations.

Table 1

Parameters of landslide causes

\begin{tabular}{|c|c|c|c|c|c|c|}
\hline Parameter (unit) & $\begin{array}{l}\text { Reading } \\
\text { (Weight) }\end{array}$ & $\begin{array}{l}\text { Percentage } \\
\text { of Weighting }\end{array}$ & $\begin{array}{l}\text { Reading } \\
\text { (Weight) }\end{array}$ & $\begin{array}{l}\text { Percentage } \\
\text { of Weighting }\end{array}$ & $\begin{array}{l}\text { Reading } \\
\text { (Weight) }\end{array}$ & $\begin{array}{l}\text { Percentage } \\
\text { of Weighting }\end{array}$ \\
\hline $\begin{array}{l}\text { Rainfall }\left(\mathrm{mm}^{3} /\right. \\
\text { hour) }\end{array}$ & $\begin{array}{c}0-20 \\
(1)\end{array}$ & $30 \%$ & $\begin{array}{c}20-40 \\
(2)\end{array}$ & $30 \%$ & $\begin{array}{c}>40 \\
(3)\end{array}$ & $30 \%$ \\
\hline Slope (degree) & $\begin{array}{l}0-30 \\
(1)\end{array}$ & $15 \%$ & $\begin{array}{l}31-70 \\
(2)\end{array}$ & $15 \%$ & $\begin{array}{l}>70 \\
(3)\end{array}$ & $15 \%$ \\
\hline $\begin{array}{l}\text { Soil Moisture } \\
(\%)\end{array}$ & $\begin{array}{c}0-30 \\
(1)\end{array}$ & $22 \%$ & $\begin{array}{l}31-35 \\
(2)\end{array}$ & $22 \%$ & $\begin{array}{l}>35 \\
(3)\end{array}$ & $22 \%$ \\
\hline $\begin{array}{l}\text { Vibration } \\
\text { (Richter's scale) }\end{array}$ & $\begin{array}{l}0-2 \\
(1)\end{array}$ & $23 \%$ & $\begin{array}{l}3-5 \\
(2)\end{array}$ & $23 \%$ & $\begin{array}{l}>5 \\
(3)\end{array}$ & $23 \%$ \\
\hline Vegetation & (2) & $10 \%$ & (2) & $10 \%$ & (2) & $10 \%$ \\
\hline
\end{tabular}


Furthermore, the vulnerability of the landslide based on (Ministry of Public Work Regulation, 2007) can be calculated using the following Equation 1.

$$
\begin{aligned}
\text { Level of vulnerability }= & \text { rainfall weight } * 30 \%+\text { slope weight } * 15 \% \\
& + \text { soilmoisture } 1 \text { weight } * 11 \%+\text { soilmoisture } 2 \text { weight } * 11 \% \\
& + \text { vibration weight } * 23 \%+2 * 10 \%
\end{aligned}
$$

Secondly, the data is applied to the algorithm of the ANN intelligence system model. The system model consists of three layers: the input layer, the hidden layer, and the output layer. The feed-forward backpropagation (FFBP) and the cascade-forward backpropagation (CFBP) methods are analyzed to predict the possibility of a landslide occurrence. Furthermore, the ANN intelligent system gives three statuses, namely safe, standby, and hazard situations. After that, the chosen result, either the FFBP or the CFBP method, will be embedded in the hardware system.

The FFBP and CFBP methods structure are shown in Figure 1(a) and 1(b), respectively. It consists of three layers: the input layer, the hidden layer, and the output layer. In the first layer, there are five input variables used, which are rainfall, slope, soil moisture with two different depths, and vibration. The second layer uses the hyperbolic tangent activation function to get a more accurate system output in predicting landslides symptoms. The activation function is applied to each neuron. Afterwards, there is an output in the scaling

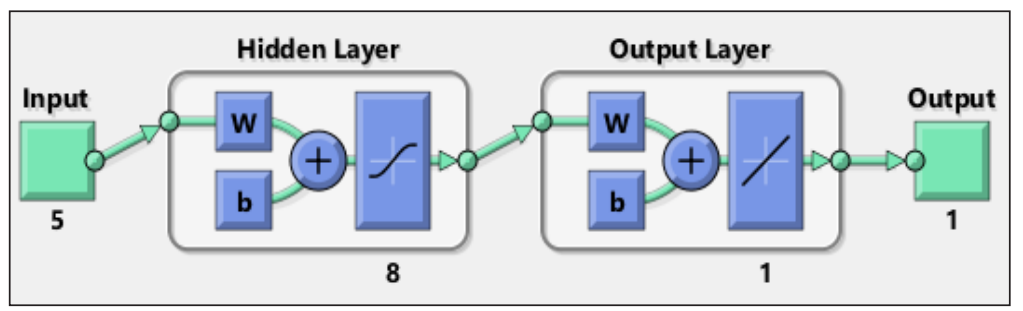

(a)

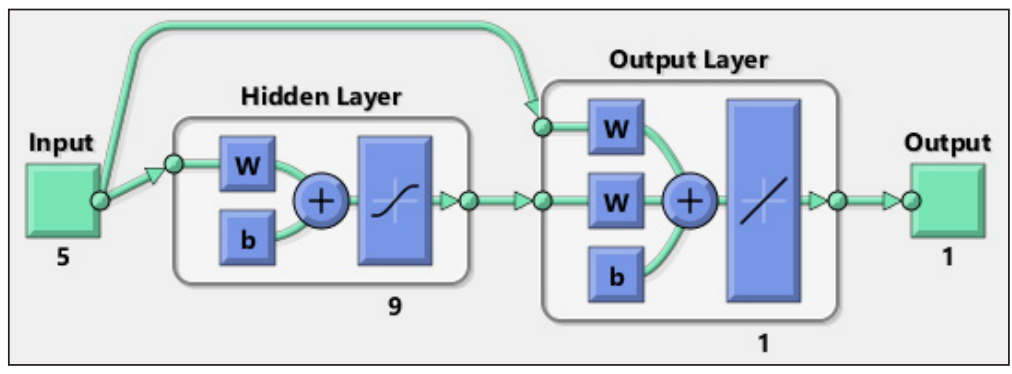

(b)

Figure 1. Structure of ANN with FFBP (a) and CFBP (b) 
form of landslide possibility level in the third layer, from scale 1 for safe situation up to scale 3 for hazard situation. Later, this ANN intelligent system will be embedded into a developed hardware system shown in Figure 2. It consists of sensors, such as a reed switch, YI-69, MPU 6050, 801S, and DHT22 ( Sofwan et al., 2018a; Sofwan et al., 2018b). The sensors measure physical parameters, such as rainfall, slope, soil moisture, and vibration. The tipping bucket calculates the number of rainfall. Sensor MPU 6050 measures slope change, especially when the landslide happens. Soil moisture sensor quantifies the level of groundwater. The $801 \mathrm{~S}$ vibration sensor gauges the amount of ground vibration. The DHT22 sensor detects temperature and air humidity. The hardware system uses the Arduino Mega 2560 as the data processing centre, which holds an appropriate ANN intelligence. The Realt Time Clock (RTC) module functions as an electronic clock, counting the system clock and keeping data in real-time. The utilization of relay and fan has a purpose of keeping cooling the hardware node, especially the microcontroller. Furthermore, the processing result is sent to the database and web server by using the SIM900A module.

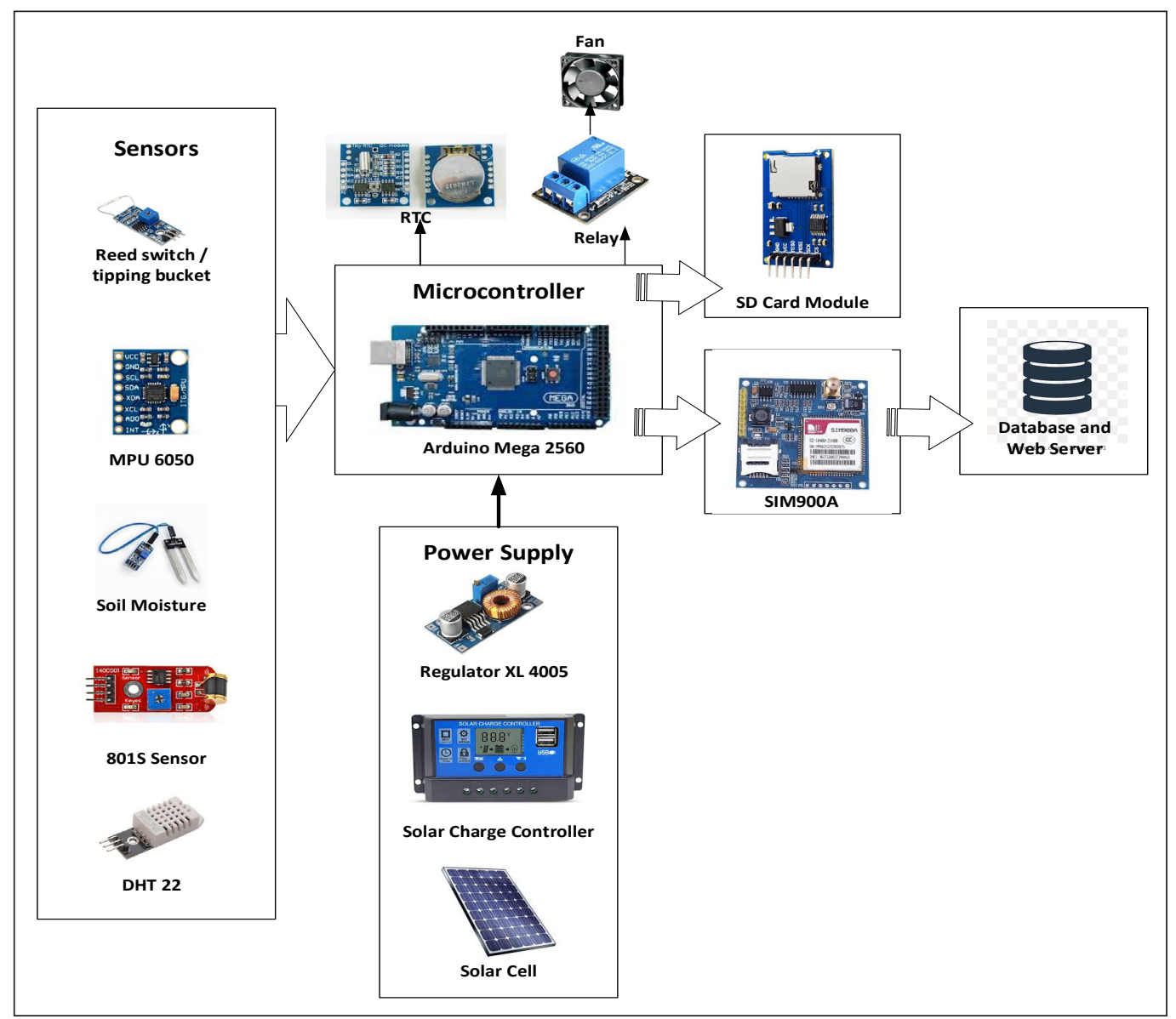

Figure 2. Overall system block diagram 


\section{Artificial Neural Network for Landslide Early Warning System}

In this section, a design of the ANN intelligent system for the early detection system of landslides using the FFBP and CFBP is described. The designed system utilized a 3-layer or multi-layer perceptron structure, namely the input layer, hidden layer, and output layer, shown in Figure 1. The following subsections describe the design of each layer for both methods in detail.

Design of Input Layer. The input layer uses five data parameter inputs: rainfall, slope, two depths of soil moisture, and vibration parameters. The rainfall parameter is obtained from the reed switch sensor in the tipping bucket. The slope parameter value is delivered by the MPU6050 sensor. The soil moisture parameters at two different depths are received from the YL-69 sensors. The aim of using two sensors in different depths is to obtain soil moisture characteristics in two levels, on the surface and in the ground. The two-level humidity strengthens the prediction of the landslide. And the last parameter, which is the vibration, is taken from the $801 \mathrm{~S}$ sensor. Furthermore, these parameters are named rainfall, slope, soilmoisture1, soilmoisture2, and vibration variables.

The ANN can process the variables if they have been normalized. Normalization is performed to simplify the calculation of weights in ANN and reduce the distance between the input data values. It also speeds up the learning process and leads to faster convergence. Therefore, the variables must be normalized before processing with ANN. In this layer, the min-max function is used to normalize the input data expressed in the following Equation 2.

$$
y=\frac{\left(x-x_{\min }\right)\left(y_{\max }-y_{\min }\right)}{x_{\max }-x_{\min }}+y_{\min }
$$

The variables $y, y_{\max }$, and $y_{\min }$ denote the obtained, the maximum, and the minimum of the normalized data. While the variables $\mathrm{x}, \mathrm{x}_{\max }$, and $\mathrm{x}_{\min }$ refer to the original, the maximum, and the minimum value of measurement data from input data per minute.

From the formula above, the minimum and maximum values can be referred to as parameter value as follows.

$\begin{array}{lll}\text { Rainfall } & =0-150(\mathrm{~mm} 3 \text { per hour }) \\ \text { Slope } & =0-100(\%) \text { which } 0 \text { is } 0 \text { degree and } 100 \text { is } 45 \text { degree } \\ \text { Soilmoisture1 } & =0-100(\%) \\ \text { Soilmoisture2 } & =0-100(\%) \\ \text { Vibration } & =0-7 \text { (Richter's Scale) }\end{array}$

Design of Hidden Layer. The hidden layer design is performed by applying variations of neurons, which provides a fast computation, and the calculation results with a little value or close to zero of error. The variety of neurons, which are applied in the hidden layer with 
a number of $5,8,9,10$, and 15 neurons. The reason for experimenting with variations in neurons is to determine the running system response with several variations of the neuron. Later on, one of the numbers of neurons with the minimum training error, i.e., close to zero, will be applied in this layer.

The hidden layer performs computation by weighting to each input value. In the FFBP method, the hidden layer's input is obtained by performing a mathematical calculation using the Equation 3.

$$
W_{f}=\sum_{k=1}^{8}\left(\left(i_{1}+i_{2}+i_{3}+i_{4}+i_{5}\right) W_{1 k}+\left(W_{1 k} . \text { Bias }_{1}\right)\right)
$$

where $\mathrm{W}_{\mathrm{f}}$ denotes the weight in the hidden layer of FFBP, $\mathrm{i}_{\mathrm{k}}$ refers to input $\mathrm{k}$-th, and Bias ${ }_{1}$ indicates the bias in the hidden layer. After some epochs, the best value of weight and bias, which results in minimum training error, is chosen in the hidden layer with eight neurons. The weight and bias are shown in Tables 2 and 3, respectively.

Furthermore, the computation in the hidden layer is conducted by multiplying the weights and biases, which are obtained from the training set, with the hyperbolic tangent activation function. The activation function is essential for the neural network model to learn and understand complex non-linear functions. They allow the introduction of nonlinear features to the network. The hyperbolic tangent activation function is shown in the following Equation 4.

$$
f(x)=\tanh \left(\frac{x}{2}\right)=\frac{1-e^{-x}}{1+e^{-x}}
$$

Table 2

Weight in the hidden layer of FFBP with eight neurons

\begin{tabular}{ccccccccc}
\hline \multirow{2}{*}{ i(input) } & \multicolumn{7}{c}{$\mathrm{W}_{1}$ (weight) } \\
\cline { 2 - 9 } & 1 & 2 & 3 & 4 & 5 & 6 & 7 & 8 \\
\hline 1 & 0.12430 & 23.87400 & 0.014135 & 0.06201 & -35.34480 & -0.03811 & -36.2062 & 43.35870 \\
2 & 0.04945 & 7.74800 & 0.007768 & 0.02425 & -0.14958 & 0.036918 & -0.15933 & 10.01040 \\
3 & 0.02935 & 34.99580 & -0.037923 & 0.01069 & 3.24120 & -0.09094 & 3.29970 & 14.36040 \\
4 & -0.25145 & 40.67150 & -0.051283 & -0.13615 & 2.76630 & 0.09815 & 2.82470 & 13.82550 \\
5 & 0.19447 & 0.073166 & 0.017005 & 0.08366 & -1.07030 & -0.02005 & -1.08850 & 3.13340 \\
\hline
\end{tabular}

Table 3

Bias in the hidden layer of FFBP with eight neurons

\begin{tabular}{ccccccccc}
\hline & \multicolumn{8}{c}{$\mathrm{W}_{1}$ (weight) } \\
\cline { 2 - 9 } & 1 & 2 & 3 & 4 & 5 & 6 & 7 & 8 \\
\hline B1 & -0.02017 & 91.4655 & 0.00797 & -0.007346 & -31.1158 & 0.064688 & -31.8737 & 69.6398 \\
\hline
\end{tabular}


where $\mathrm{x}$ denotes the input value of weight and bias. Furthermore, the obtained weight and bias values will be forwarded to the output layer.

In the CFBP method, the input of the hidden layer is calculated using a formula, which operates nine neurons instead of eight, as Equation 5.

$$
W_{c}=\sum_{k=1}^{9}\left(\left(i_{1}+i_{2}+i_{3}+i_{4}+i_{5}\right) W_{1 k}+\left(W_{1 k} \cdot \text { Bias }_{1}\right)\right)
$$

where $\mathrm{W}_{\mathrm{c}}$ denotes the weight in the hidden layer of CFBP. The weight and bias values are shown in Tables 4 and 5, respectively. Furthermore, similar to the FFBP method, computation in this layer also is performed by multiplying with the tanh activation function.

Design of the Output Layer. The output layer design uses one neuron, with input from the hidden layer multiplied by the second weighting. The output layer is then added by weighting the input from the input layer to obtain new weight and bias values. In the FFBP and CFBP methods, the new weight and bias values are shown in Tables 6 and 7, respectively.

Table 6 shows that the weight and bias values in the output layer of FFBP are obtained by performing mathematical calculations using the following Equation 6 .

$$
x=\sum_{k=1}^{8}\left(\left(W_{f} \cdot W_{2 k}\right)+\left(W_{2 k} \cdot \text { Bias }_{2}\right)\right)
$$

where $\mathrm{x}$ refers to the output layer's result, $\mathrm{W}_{2}$ denotes weight in the output layer, and $\mathrm{Bias}_{2}$ indicates the bias in the output layer.

Table 4

Weight in the hidden layer of the CFBP with nine neurons

\begin{tabular}{cccccccccc}
\hline $\mathrm{i}$ & \multicolumn{7}{c}{$\mathrm{W}_{\text {1 }}$ (weight) } \\
\cline { 2 - 10 } (input) & 1 & 2 & 3 & 4 & 5 & 6 & 7 & 8 & 9 \\
\hline 1 & 1.1647 & -1.1811 & 0.065471 & 0.50684 & 1.0310 & 1.3121 & 0.16789 & -1.0794 & -1.0587 \\
2 & -1.2763 & 1.4417 & -0.91833 & 0.89618 & -0.7197 & 1.3052 & -0.58401 & -0.7623 & -0.76754 \\
3 & 0.50112 & -0.19541 & -0.56255 & 0.81184 & 0.22198 & 0.0666 & 1.616 & -0.5104 & 0.74318 \\
4 & 1.1795 & -0.65703 & 0.30079 & -1.166 & -1.182 & 0.0955 & 1.066 & 1.0743 & -0.9955 \\
5 & 0.28405 & -0.17847 & -1.7925 & -0.38268 & -0.8963 & 0.9124 & -0.7575 & -0.1675 & -0.94622 \\
\hline
\end{tabular}

Table 5

Bias in the hidden layer of CFBP with nine neurons

\begin{tabular}{cccccccccc}
\hline & \multicolumn{8}{c}{$\mathrm{W}_{1}$ (weight) } \\
\cline { 2 - 10 } & 1 & 2 & 3 & 4 & 5 & 6 & 7 & 8 & 9 \\
\hline B1 & -2.1337 & 1.7003 & -1.0764 & -0.38706 & 0.047341 & 0.49982 & 1.0936 & -1.6464 & -2.1233 \\
\hline
\end{tabular}


Table 7 shows that the weight and bias values in the output layer of CFBP are obtained by performing mathematical calculations using the Equation 7.

$$
x=\sum_{k=1}^{9}\left(\left(W_{c} \cdot W_{3 k}\right)+\left(\left(i_{1}+i_{2}+i_{3}+i_{4}+i_{5}\right) \cdot W_{2 k}\right)+\left(W_{3 k} \cdot \text { Bias }_{2}\right)\right)[7]
$$

where $\mathrm{x}$ refers to the output layer result, $\mathrm{W}_{2}$ and $\mathrm{W}_{3}$ denote weight in the output layer, and Bias $_{2}$ indicates the bias in the output layer.

The output layer result must be multiplied by the activation function. The activation function used is a linear function, as shown in the following Equation 8.

$$
y=f(x)=x
$$

After getting one output variable from the output layer, the next process is to normalize the data again, to return the data to its original form using the min-max reverse function (Equation 9).

Table 6

Weight and bias in the output layer of FFBP

\begin{tabular}{ccc}
\hline No. & $\mathrm{W}_{2}$ (Weight) & Bias $_{2}$ \\
\hline 1 & -1.3237 & \\
2 & 0.013994 & \\
3 & -15.0164 & \\
4 & 11.3335 & -0.098634 \\
5 & -0.76339 & \\
6 & 4.0832 & \\
7 & 0.76187 & \\
8 & -0.01352 & \\
\hline
\end{tabular}

Table 7

Weight and bias in the output layer of CFBP

\begin{tabular}{lccl}
\hline \multirow{2}{*}{ No. } & \multicolumn{2}{c}{$\mathrm{W}_{2}$ (weight) } & Bias $_{2}$ \\
\cline { 2 - 3 } & 2 & 3 & \\
2 & 0.11734 & $-5.5917 \mathrm{e}-17$ & \\
3 & 0.25938 & $-5.2874 \mathrm{e}-17$ & \\
4 & 0.30466 & $-4.2555 \mathrm{e}-17$ & -0.0097987 \\
5 & -0.02882 & $-4.1597 \mathrm{e}-17$ & \\
6 & 0.35765 & $-5.9389 \mathrm{e}-17$ & \\
7 & & $-1.7423 \mathrm{e}-17$ & \\
8 & & $-6.4548 \mathrm{e}-18$ & \\
9 & & $2.5679 \mathrm{e}-17$ & \\
\hline
\end{tabular}




$$
x=\frac{\left(y-y_{\min }\right)\left(x_{\max }-x_{\min }\right)}{y_{\max }-y_{\min }}+x_{\min }
$$

where $\mathrm{x}$ is the postprocessing output, $\mathrm{y}$ is the input of the output layer, $\mathrm{x}_{\min }$ is the minimum output value, $x_{\max }$ is the maximum output value, $y_{\min }$ is the minimum weighting value, and $\mathrm{y}_{\max }$ is the maximum weighting value.

Program Design at Arduino Mega 2560. The hardware system utilizes Arduino Mega 2560 microcontroller as the mainboard of the hardware system. The microcontroller runs the program with a designed ANN method. The algorithm performs some steps similar to the ANN model system, which obtain five input data from sensors, performs calculation of weight and bias, calculates the hidden layer's value, and conducts postprocessing of the output ANN. The flowchart of the ANN program in the microcontroller is shown in Figure 3. Furthermore, the implementation program in the microcontroller is using Arduino IDE software.

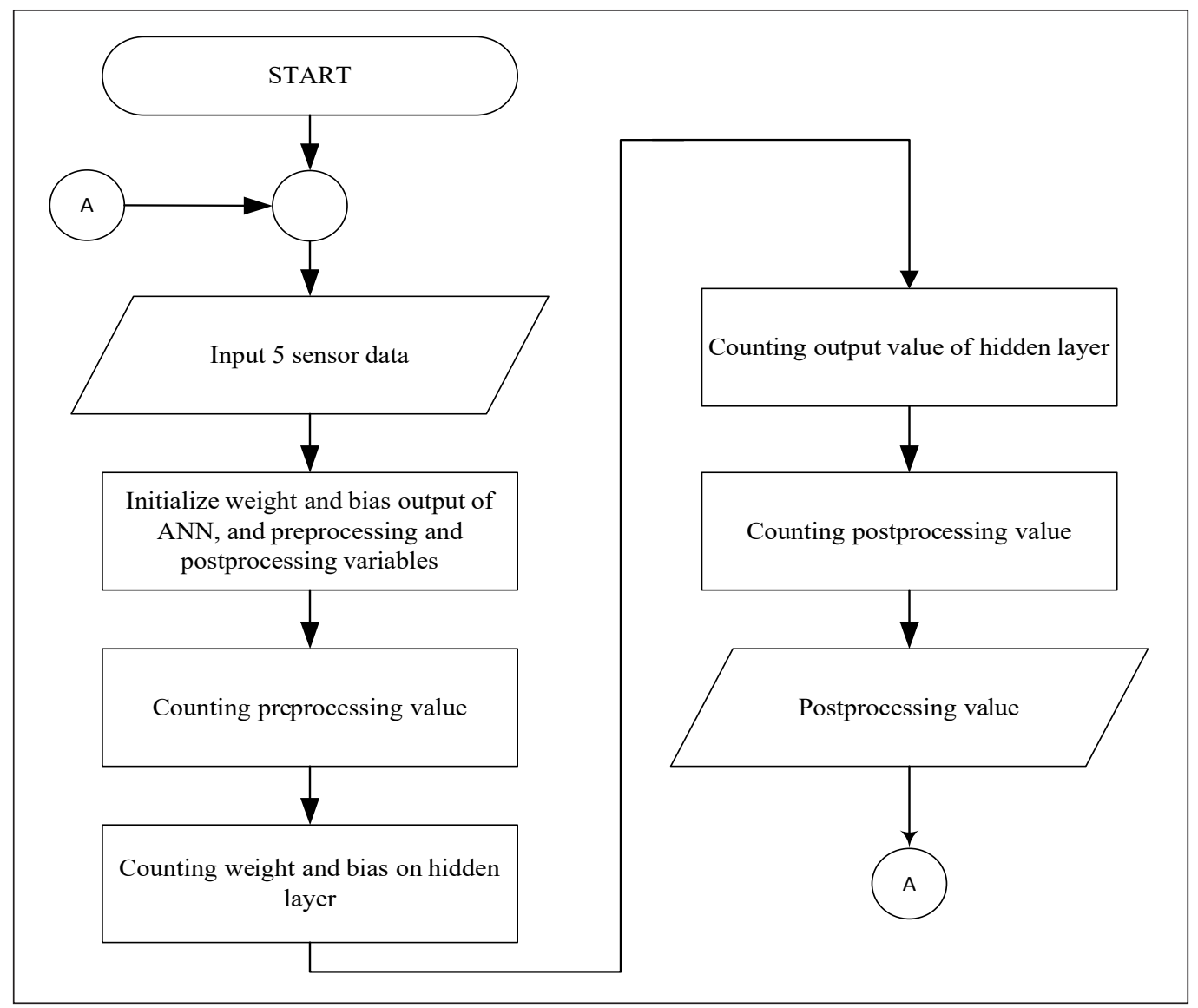

Figure 3. Flow chart of the ANN system 


\section{RESULTS AND DISCUSSION}

This section evaluates and discusses the ANN intelligent system performance in three levels of vulnerability of a landslide: safe, standby, and hazard conditions. The evaluation testing was applied to the FFBP and CFBP methods. The results of testing are complemented with detailed discussions.

\section{ANN System Testing on the Safe Condition}

The system testing was conducted to see the FFBP and CFBP methods' performance in terms of minimum square error (MSE). The five parameters, which are rainfall, slope, soil moisture 1, soil moisture 2, and vibration, are delivered to the ANN methods. Table 8 exposes the input data samples. The testing was carried out with ten samples as input data to examine both methods.

Furthermore, the output values of both methods' output values are compared to that of the manual calculation. The manual calculation is obtained by using a mathematical equation, which is expressed in Equation 1. The score range of safe condition, which is according to Equation 1, is in range with a value of 1 to 1.69. According to data in Table 8 , the manual calculation results in an amount of 1.32 , which is in the safe condition level. Table 9 exposes the manual calculation and results of the ANN system with the FFBP and CFBP methods in safe conditions.

The error is obtained from the difference between the value of manual calculation and the value of a method. Hereafter, in the safe condition from Table 10, it can be seen the MSE of the FFBP and CFBP are 0.017076 and 0.034952 , respectively. The former method performance is better than that of the latter, with a different value of 0.017876 . This difference in error value is caused by differences in structure and weight values used in each method.

Tabel 8

The input of ANN system testing on safe condition data

\begin{tabular}{llllll}
\hline No. & Rainfall $\left(\mathrm{mm}^{3}\right)$ & Slope $(\%)$ & Soil Moisture 1 (\%) & Soil Moisture 2 (\%) & Vibration \\
\hline 1 & 0 & 2.12 & 42 & 8.3 & 0 \\
2 & 0 & 3.34 & 45 & 8.6 & 0 \\
3 & 0 & 0.88 & 43 & 8.6 & 0 \\
4 & 0 & 2 & 42 & 8.5 & 0 \\
5 & 0 & 3.1 & 41 & 8.5 & 0 \\
6 & 0 & 1.8 & 43 & 8.1 & 0 \\
7 & 0 & 1.9 & 42 & 7.98 & 0 \\
8 & 0 & 2.06 & 43 & 7.90 & 0 \\
9 & 0 & 3.76 & 45 & 9.1 & 0 \\
10 & 0 & 4.15 & 47 & 8.98 & 0 \\
\hline
\end{tabular}


Table 9

Result of ANN system output on safe condition

\begin{tabular}{lcccccccc}
\hline No. & Manual Calculation & Status & FFBP & Status & Error & CFBP & Status & Error \\
\hline 1 & 1.32 & Safe & 1.350 & Safe & 0.030 & 1.2896 & Safe & 0.0304 \\
2 & 1.32 & Safe & 1.331 & Safe & 0.011 & 1.2897 & Safe & 0.0303 \\
3 & 1.32 & Safe & 1.331 & Safe & 0.011 & 1.2884 & Safe & 0.0316 \\
4 & 1.32 & Safe & 1.342 & Safe & 0.022 & 1.2862 & Safe & 0.0338 \\
5 & 1.32 & Safe & 1.3176 & Safe & 0.0026 & 1.2771 & Safe & 0.0429 \\
6 & 1.32 & Safe & 1.330 & Safe & 0.010 & 1.2848 & Safe & 0.0352 \\
7 & 1.32 & Safe & 1.342 & Safe & 0.022 & 1.2870 & Safe & 0.0330 \\
8 & 1.32 & Safe & 1.344 & Safe & 0.024 & 1.2854 & Safe & 0.0346 \\
9 & 1.32 & Safe & 1.330 & Safe & 0.010 & 1.2811 & Safe & 0.0389 \\
10 & 1.32 & Safe & 1.3249 & Safe & 0.0049 & 1.2832 & Safe & 0.0368 \\
\hline
\end{tabular}

\section{ANN System Testing on Standby Condition}

The system testing in the alert condition was also conducted to see the performance of both FFBP and CFBP methods. The input data that is used as the samples can be seen in Table 10 . The testing was held by using ten samples to examine the output testing of both methods.

Similar to the testing of the safe condition, the result values of the output layer of FFBP and CFBP methods are also compared to that of the manual calculation. The score range of standby condition, which is according to Equation 1, is in range with a value of 1.7 to 2.39. According to data in Table 10, the manual calculation results in variation values in the standby condition level. Table 11 exhibits the manual calculation results and results of the ANN system testing with FFBP and CFBP methods.

Table 11 shows the MSE of the FFBP and CFBP are 0.049597 and 0.046764, respectively. The former method performance is less than that of the latter, with a different value of 0.002833 .

\section{ANN System Testing on the Hazardous Condition}

The ANN system testing on the hazardous condition was also held with goals to perceive the achievement of the FFBP and the CFBP methods. The input data samples that are utilized in this testing can be seen in Table 12. The testing was held by using those samples to examine the output testing of both methods. Meanwhile, the range of scores that state the hazard condition is in a value of 2.4 to 3, which is referred to Equation 1.

Referring to data in Table 12, the manual calculation results in variation values in a range between 2.40-3.00, which are in the standby condition level. Table 13 exhibits the results of the manual calculation and results of the FFBP and CFBP methods. Table 13 shows the error of the FFBP and the CFBP in each sample. Furthermore, the MSE of the 
Tabel 10

The input of the ANN system testing with standby condition

\begin{tabular}{cccccc}
\hline No. & Rainfall $\left(\mathrm{mm}^{3}\right)$ & Slope $(\%)$ & Soil Moisture 1 $(\%)$ & Soil Moisture 2 (\%) & Vibration \\
\hline 1 & 56 & 16.12 & 42.2 & 32.3 & 4 \\
2 & 61 & 39.34 & 45.5 & 33.6 & 4 \\
3 & 34 & 40.88 & 43.7 & 18.6 & 7 \\
4 & 32 & 52.2 & 42.6 & 38.5 & 2 \\
5 & 48 & 53.1 & 41.6 & 48.2 & 2 \\
6 & 67 & 23.8 & 43.2 & 33.1 & 5 \\
7 & 69 & 40.9 & 42.3 & 32.98 & 7 \\
8 & 66 & 32.06 & 43.2 & 49.9 & 3 \\
9 & 60 & 33.76 & 45.8 & 59.1 & 2 \\
10 & 57 & 14.15 & 47.1 & 48.98 & 4 \\
\hline
\end{tabular}

Tabel 11

Result of the ANN system testing on standby condition

\begin{tabular}{ccccccccc}
\hline No. & Manual Calculation & Status & FFBP & Status & Error & CFBP & Status & Error \\
\hline 1 & 2.15 & Standby & 2.1974 & Standby & 0.0474 & 2.1642 & Standby & 0.0142 \\
2 & 2.03 & Standby & 2.0366 & Standby & 0.0066 & 2.0281 & Standby & 0.0019 \\
3 & 2.27 & Standby & 2.2174 & Standby & 0.0526 & 2.2547 & Standby & 0.1153 \\
4 & 2.18 & Standby & 2.151 & Standby & 0.029 & 2.2048 & Standby & 0.0248 \\
5 & 2.29 & Standby & 2.2952 & Standby & 0.0052 & 2.2869 & Standby & 0.0031 \\
6 & 2.11 & Standby & 2.196 & Standby & 0.086 & 2.0163 & Standby & 0.0937 \\
7 & 2.11 & Standby & 2.1532 & Standby & 0.0432 & 2.1747 & Standby & 0.0647 \\
8 & 2.22 & Standby & 2.1885 & Standby & 0.0315 & 2.2706 & Standby & 0.0506 \\
9 & 2.07 & Standby & 2.1006 & Standby & 0.0306 & 2.1394 & Standby & 0.0694 \\
10 & 1.88 & Standby & 1.7935 & Standby & 0.0865 & 1.8585 & Standby & 0.0615 \\
\hline
\end{tabular}

Table 12

The input of the ANN system testing with hazard condition

\begin{tabular}{cccccc}
\hline No. & Rainfall $\left(\mathrm{mm}^{3}\right)$ & Slope $(\%)$ & Soil Moisture 1 $(\%)$ & Soil Moisture 2 $(\%)$ & Vibration \\
\hline 1 & 128 & 76.12 & 61.23 & 58.30 & 5 \\
2 & 61 & 59.34 & 59.21 & 58.60 & 7 \\
3 & 94 & 60.88 & 33.00 & 31.60 & 7 \\
4 & 72 & 42.20 & 47.00 & 38.50 & 6 \\
5 & 88 & 73.10 & 61.00 & 39.20 & 6 \\
6 & 87 & 83.80 & 73.00 & 78.10 & 6 \\
7 & 99 & 74.90 & 62.00 & 47.98 & 6 \\
8 & 106 & 82.06 & 33.30 & 32.90 & 5 \\
9 & 90 & 83.76 & 48.00 & 49.10 & 7 \\
10 & 97 & 74.15 & 77.3 & 68.98 & 6 \\
\hline
\end{tabular}


Table 13

Result of the ANN system on hazard condition

\begin{tabular}{ccccccccc}
\hline No. & Manual Calculation & Status & FFBP & Status & Error & CFBP & Status & Error \\
\hline 1 & 2.67 & Hazard & 2.7026 & Hazard & 0.0326 & 2.7297 & Hazard & 0.0597 \\
2 & 2.52 & Hazard & 2.4822 & Hazard & 0.0378 & 2.4835 & Hazard & 0.0365 \\
3 & 2.68 & Hazard & 2.5614 & Hazard & 0.1186 & 2.6186 & Hazard & 0.0614 \\
4 & 2.67 & Hazard & 2.7044 & Hazard & 0.0344 & 2.7527 & Hazard & 0.0827 \\
5 & 2.67 & Hazard & 2.6153 & Hazard & 0.0547 & 2.6297 & Hazard & 0.0403 \\
6 & 2.90 & Hazard & 2.8291 & Hazard & 0.0709 & 2.8799 & Hazard & 0.0201 \\
7 & 2.67 & Hazard & 2.7196 & Hazard & 0.0496 & 2.7374 & Hazard & 0.0674 \\
8 & 2.45 & Hazard & 2.4917 & Hazard & 0.0417 & 2.4894 & Hazard & 0.0394 \\
9 & 2.67 & Hazard & 2.633 & Hazard & 0.037 & 2.6674 & Hazard & 0.0026 \\
10 & 2.90 & Hazard & 2.8149 & Hazard & 0.0851 & 2.7869 & Hazard & 0.1131 \\
\hline
\end{tabular}

FFBP and CFBP are 0.062105 and 0.060355 , respectively. These MSE values indicate that the former method performance is less than that of the latter, with a different amount of 0.00175 .

Based on the testing in three levels of vulnerability of the landslide, both methods performance of each level is obtained. The FFBP method performance is better than that of the CFBP method in terms of safe condition level. In contrast, the CFBP method is superior to the FFBP method in standby and hazard conditions. CFBP model provides a connection from the input layer to the hidden layer and a direct connection to the output layer. Data from the input layer then will be weighted in the hidden layer and output layer. With this direct connection, the weighting process is more quickly performed. So that the CFBP method more appropriate for dynamic input parameters. Therefore, we deploy the ANN CFBP method into the developed hardware system. The hardware system was installed in the middle of the hill, a landslide-prone area with coordinates $-7.3406467,110.3829545$.

\section{CONCLUSION}

This paper has performed and analyzed the ANN intelligent system with the FFBP and the CFBP methods for a landslide early warning system. The intelligent system uses sensors to obtain landslide causative parameters: rainfall, the slope of the ground, soil moisture, and vibration. The ANN system output delivers three landslide vulnerability levels: safe, standby, and hazardous conditions. The MSE results of FFBP and CFBP in the safe, the standby, and the hazardous conditions are 0.017076 and $0.034952 ; 0.049597$ and 0.046764 ; 0.062105 and 0.060355 ; respectively. Based on the performed testing evaluation, the MSE of the CFBP method is superior to that of the FFBP method in terms of standby and hazardous conditions. 


\section{ACKNOWLEDGMENTS}

This work was supported by the Superior Applied Research of Higher Education (Penelitian Terapan Unggulan Perguruan Tinggi - PTUPT) Diponegoro University grant in 2019. The authors are grateful for this support.

\section{REFERENCES}

BNPB. (2019). Indonesia's disaster data information. National Disaster Management Agency. Retrieved November 11, 2020, from http://dibi.bnpb.go.id/

Borujeni, M. S., \& Nateghi, S. (2019, April 11-14). Modeling of sensor network for autonomous landslide monitoring based on neural network. In Proceeding of the IEEE SoutheastCon 2019 (pp.1-5). Huntsville, Alabama, USA. https://doi.org/10.1109/SoutheastCon42311.2019.9020350

Chaturvedi, P., Srivastava, S., \& Kaur, P. B. (2017, April 13). Landslide early warning system development using statistical analysis of sensors' data at tangni landslide, Uttarakhand, India. In Proceedings of Sixth International Conference on Soft Computing for Problem Solving (pp. 259-270). Singapore. https://doi. org/10.1007/978-981-10-3325-4_26

Chen, F., Yu, B., Xu, C., \& Li, B. (2017). Landslide detection using probability regression, a case study of Wenchuan, northwest of Chengdu. Applied Geography, 89, 32-40. https://doi.org/10.1016/j. apgeog.2017.10.001

Elsafi, S. H. (2014). Artificial neural networks (ANNs) for flood forecasting at Dongola Station in the River Nile, Sudan. Alexandria Engineering Journal, 53(3), 655-662. https://doi.org/10.1016/j.aej.2014.06.010

Gu, S., Sun, X., Wu, Y., \& Cui, Z. (2012, May 29-31). An approach to forecast red tide using generalized regression neural network. In Proceeding of the 8th International Conference on Natural Computation 2012 (pp. 194-198). Sichuan, China. https://doi.org/10.1109/ICNC.2012.6234545

Hemalatha, T., Ramesh, M. V., \& Rangan, V. P. (2019). Effective and accelerated forewarning of landslides using wireless sensor networks and machine learning. IEEE Sensors Journal, 19(21), 9964-9975. https:// doi.org/10.1109/JSEN.2019.2928358

Huang, L. J., \& Lin, X. S. (2002). Study on landslide related to rainfall. Journal of Xiangtan Normal University, 24(4), 55-62.

Li, Y. X., \& Jiang, L. C. (2010). Application of ANN algorithm in tree height modeling. Applied Mechanics and Materials, 20-23, 756-761. https://doi.org/10.4028/www.scientific.net/AMM.20-23.756

Ministry of Public Work Regulation. (2007). Guidelines for spatial planning for disaster-prone areas, regulation of the minister of public works No. 22/PRT/M/2007. Retrieved November 11, 2020, from http://landspatial. bappenas.go.id/komponen/peraturan/the_file/permen22_2007.pdf

Nguyen, V., Pham, B., Vu, B., Prakash, I., Jha, S., Shahabi, H., Shirzadi, A., Ba, D. N., Kumar, R., Chatterjee, J. M., \& Bui, D. T. (2019). Hybrid machine learning approaches for landslide susceptibility modeling. Forests, 10(2), 157. https://doi.org/10.3390/f10020157 
Pradhan, B., \& Lee, S. (2010). Regional landslide susceptibility analysis using backpropagation neural network model at Cameron Highland, Malaysia. Landslides, 7(1), 13-30. https://doi.org/10.1007/s10346-0090183-2

Radfard, M., Soleimani, H., Nabavi, S., Hashemzadeh, B., Akbari, H., Akbari, H., \& Adibzadeh, A. (2018). Data on estimation for sodium absorption ratio: Using artificial neural network and multiple linear regressions. Data in Brief, 20, 1462-1467. https://doi.org/10.1016/j.dib.2018.08.205

Sofwan, A., Sumardi, R. M. I., Goni, A., \& Najib. (2017, October 18-19). Wireless sensor network design for landslide warning system in IoT architecture. In Proceeding of the 4th International Conference on Information Technology, Computer, and Electrical Engineering (ICITACEE) 2017 (pp. 280-283). Semarang, Indonesia. https://doi.org/10.1109/ICITACEE.2017.8257718

Sofwan, A., Sumardi, R. M. I., \& Najib. (2018a, October 16-17). Measurement design of sensor node for landslide disaster early warning system [Paper presented]. 2nd International Conference on Electrical Engineering and Informatics (ICon EEI) 2018 (pp. 75-80). Batam, Indonesia. https://doi.org/10.1109/ ICon-EEI.2018.8784341

Sofwan, A., Sumardi, R. M. I., \& Ulwiyati, N. (2018b, September 26-27). Filtering for data acquisition on wireless sensor network. In Proceeding of the 5th International Conference on Information Technology, Computer and Electrical Engineering (ICITACEE) 2018 (pp.180-184). Semarang, Indonesia. https://doi. org/10.1109/ICITACEE.2018.8576940

Stangierski, J., Weiss, D., \& Kaczmarek, A. (2019). Multiple regression models and artificial neural network (ANN) as prediction tools of changes in overall quality during the storage of spreadable processed Gouda cheese. European Food Research and Technology, 245(11), 2539-2547. https://doi.org/10.1007/ s00217-019-03369-y

Tsakiri, K., Marsellos, A., \& Kapetanakis, S. (2018). Artificial neural network and multiple linear regression for flood prediction in Mohawk River, New York. Water - Open Access Journal, 10(9), 20. https://doi. org/10.3390/w10091158

Ul-Saufie, A. Z., Yahaya, A. S., Nor, Y., Hazrul, A., \& Hamid, H. A. (2011). Comparison between multiple linear regression and feed forward back propagation neural network models for predicting PM 10 concentration level based on gaseous and meteorological parameters. International Journal of Applied Science and Technology, 1(4), 42-49. 